\title{
Editorial
}

\section{Los retos de la Iglesia salvadoreña}

El nombramiento de Mons. Fernando Sáenz Lacalle como nuevo arzobispo de San Salvador ha sido interpretado unánimemente como una ruptura. Unos interpretan el nombramiento como una ruptura con la tradición profética y martirial de la arquidiócesis, pero otros consideran que es una rectificación y una recuperación de las tradiciones de comienzos de siglo. Es prematuro predecir ahora cuál de estas dos interpretaciones es correcta porque el futuro de la Iglesia arquidiocesana dependerá de la dirección que le imprima el nuevo arzobispo y de la conducta del clero, los religiosos y las religiosas, las comunidades y los fieles en general. Indudablemente, el arzobispo es muy importante para la configuración de la arquidiócesis, pero es igualmente cierto que la arquidiócesis es determinante para configurar al arzobispo.

Lo que sí puede hacerse desde ya es identificar los retos que la arquidiócesis de San Salvador tiene planteados en esta época de postguerra. Estos desafíos vienen impuestos por la realidad nacional y son independientes de la persona del arzobispo. Asimismo, estos retos no sólo cuestionan a la arquidiócesis, sino también a toda la Iglesia católica salvadoreña y a la sociedad en su conjunto. El relevo en la dirección de la arquidiócesis es una oportunidad para hacer un alto en la marcha rutinaria, examinar esos desafios y proponer medidas eclesiales para enfrentarlos. En esto, la arquidiócesis está en una posición privilegiada y tiene una responsabilidad singular.

Es claro que cada obispo es responsable de su propia diócesis y que el arzobispo no los representa; pero también es igualmente evidente que el arzobispo de San Salvador, por razones de orden social y por tradición, se convierte, muy a su pesar y prescindiendo de lo establecido por el derecho canónico, en el representante y vocero de la Iglesia católica salvadoreña. Reconociendo este hecho social, en este editorial 


\section{Ninguno de los obispos salvadoreños puede ignorar que la mayoría de sus diocesanos son pobres.}

queremos reflexionar sobre los retos que la realidad salvadoreña plantea no sólo la Iglesia y en particular a la arquidiócesis de San Salvador, sino también a toda la sociedad.

Comenzaremos esta reflexión por los desafíos planteados por la realidad actual del país, dejando para el final el gran desafio de la evangelización. Pero no porque aquélla sea más importante que ésta para la Iglesia, sino porque tal como lo declara la Evangelii Nuntiandi, "la evangelización no sería completa si no tuviera en cuenta la interpretación recíproca que en el curso de los tiempos se establece entre el evangelio y la vida concreta, personal y social" ( $\left.N^{o} 29\right)$. Precisamente por eso, la evangelización, según esta encíclica de Pablo VI, implica un "mensaje explícito" sobre los derechos y deberes de la persona, sobre la vida familiar, comunitaria, social e internacional, sobre la paz, la justicia y el desarrollo, y. un mensaje "especialmente vigoroso... sobre la liberación" (ib.).

El primer reto es la pobreza de la población. Las estadísticas muestran cómo la brecha entre ricos y pobres se abre cada vez más. Mientras la riqueza se concentra aceleradamente en círculos muy exclusivos, la clase media tiende a reducirse, desplazándose hacia la línea de la pobreza, y a los que ya son pobres se les hace más difícil superar dicha línea. Detrás de las estadísticas están las personas y las familias que se esfuerzan por resistir los embates de la dinámica empobrecedora. Pero la mayoría de las veces, sus esfuerzos no tienen éxito, porque la dinámica capitalista es mucho más fuerte. Juan Pablo II, al comienzo de su pontificado, al inaugurar la conferencia episcopal latinoamericana de Puebla, condenó esa brecha como "un escándalo y una contradicción con el ser cristiano" $(I I, 2)$ y recogiendo una denuncia de su predecesor calificó como un insulto "el lujo de unos pocos" frente a "la miseria de las grandes masas" (ib.). Por consiguiente, "por un auténtico compromiso evangélico", señaló Juan Pablo II en el discurso citado, la Iglesia "debe hacer oír su voz denunciando y condenando estas situaciones, más aún cuando los gobernantes se profesan cristianos" (Puebla, 42).

La extensión y la profundización de la pobreza se encuentran más allá de las voluntades y los esfuerzos de los salvadoreños afectados negativamente, pero no más allá de las decisiones de quienes se enriquecen escandalosamente, pues con ellas ratifican los mecanismos y dinamismos capitalistas. Ello exige continuos y claros llamados a la conversión personal. Por eso, Juan Pablo II, en la encíclica Sollicitudo rei socialis, sostiene que se debe hablar de ' 'estructuras de pecado', las 
cuales... se fundan en el pecado personal $y$, por consiguiente están unidas siempre a actos concretos de las personas, que las introducen, $y$ hacen difícil su eliminación... Y asi estas mismas estructuras se refuerzan, se difunden y son fuente de otros pecados, condicionando la conducta de los hombres" ( $\left.N^{\circ} 36\right)$.

Después de la cumbre sobre el desarrollo social de Copenhague, el gobierno salvadoreño anunció planes para ayudar a aliviar y erradicar la pobreza. Incluso se comprometió a adoptar ciertas medidas. Sin

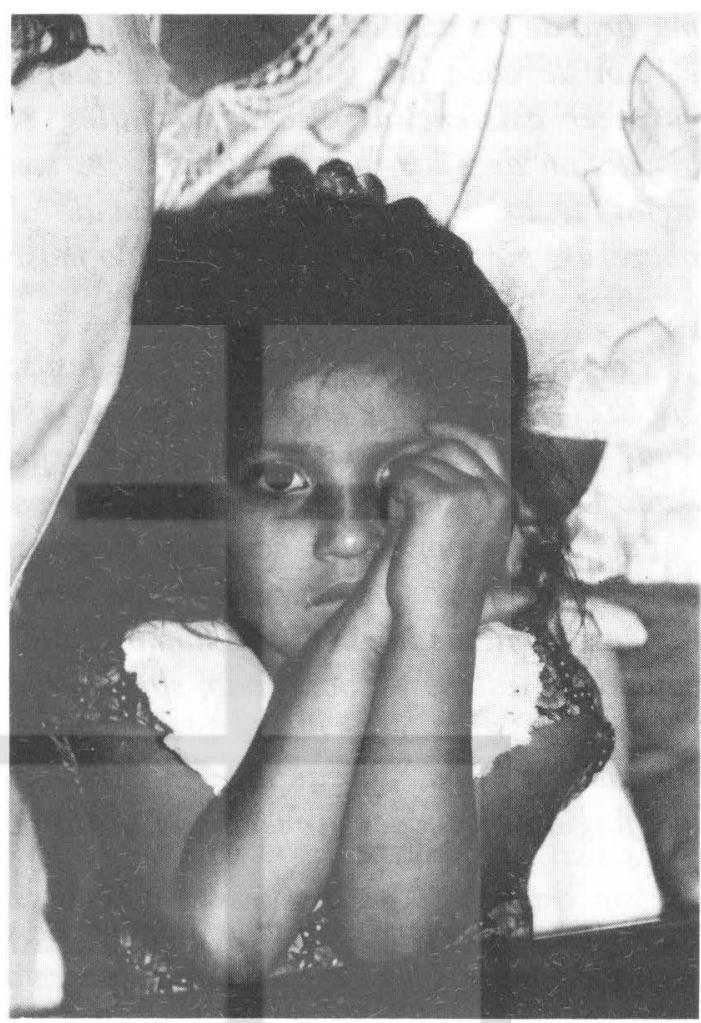
embargo, hasta ahora, esos anuncios sólo se han concretizado en nuevos impuestos. El gobierno se ha limitado a publicitar algunos programas asistencialistas, orientados a paliar algunos efectos de la pobreza, pero la escasez de recursos económicos impide que ese asistencialismo sea masivo. Para erradicar la pobreza hay que atender sus causas y esto requiere de un plan económico social integrado, coherente y de gran envergadura. En estos momentos, las políticas gubernamentales están orientadas a consolidar el modelo del rebalse, es decir, a favorecer a los minoritarios sectores financiero, comercial e industrial, esperando que los demás se beneficien de lo que a éstos les sobre. En otras palabras, no parece que el gobierno actual cuente con los planes y recursos para comenzar a erradicar la pobreza del país. Más aún, si mantiene la política actual, la dinámica empobrecedora continuará cobrando víctimas.

La Iglesia católica no puede soslayar este dato primario, sino que debe tomar una postura firme y clara a partir de su compromiso con el evangelio de Jesús y de su fidelidad a su magisterio social. Ninguno de los obispos salvadoreños puede ignorar que la mayoría de sus diocesanos son pobres que luchan por asegurar el empleo, la alimentación, la salud, la educación y la vivienda. Tampoco pueden ignorar la violencia estructural y generalizada de la cual son víctimas. La inmensa 
mayoría de los católicos son pobres que viven angustiados por conseguir el pan de cada día y asegurar su integridad física. Las medidas de carácter asistencial pueden ser útiles, sobre todo para quienes se benefician de ellas, pero a todas luces son insuficientes porque, en el mejor de los casos, sólo se ocupan de algunos de los efectos de la pobreza y porque ésta es un fenómeno masivo que aquéllas no alcanzan a cubrir.

Por fidelidad a las enseñanzas de Jesús, al magisterio pontificio sobre la cuestión social, en particular las tres últimas encíclicas sobre este tema, y al magisterio latinoamericano, expresado en Medellín, Puebla y Santo Domingo, la Iglesia tiene que optar por lo que Juan Pablo II llama "la opción o amor preferencial por los pobres" que, según sus palabras, es una "preocupación acuciante" que "no puede dejar de abarcar a las inmensas muchedumbres de hambrientos, mendigos, sin techo, sin cuidados médicos y, sobre todo, sin esperanza de un futuro mejor" (ib., $N^{\circ} 42$ y 43). "No se puede olvidar la existencia de esa realidad", continúa el Papa, porque eso "significaría parecernos al rico Epulón que fingía no conocer al mendigo Lázaro postrado a su puerta" (ib., $N^{\circ}$ 42).

Se trata de defender la vida de miles de salvadoreños y salvadoreñas "a todos los niveles, en acciones concretas hasta alcanzar decididamente algunas reformas necesarias" (ib., $N^{\circ} 43$ ). No hay que olvidar que la raíz de la descomposición social y personal está en la pobreza y en el orden que la reproduce y la expande. Es poco eficaz insistir en los valores morales cuando hay tanta miseria y deshumanización. Ya santo Tomás de Aquino afirma un principio básico de la moral cristiana: para poder ser sujeto responsable de los propios actos, antes es necesario tener satisfechos los niveles primarios de la vida.

El segundo reto que tienen planteado el pueblo salvadoreño y, por consiguiente, la Iglesia católica y sus pastores es la continuidad y profundización del proceso iniciado con la firma de los acuerdos de paz. Con demasiada facilidad se tiende a decir que los compromisos adquiridos en los acuerdos ya han sido cumplidos, implicando con ello que de éstos ya no se debe esperar nada más. Sin desconocer los esfuerzos hechos para finalizar la guerra, incorporar a la dirigencia de la ex guerrilla en la vida nacional y abrir espacios para el debate público, hay que reconocer objetivamente que la mayoría de los compromisos se han cumplido más formal que realmente.

Un poco más de la tercera parte de la opinión pública pondera más los fracasos sobre los logros del proceso de transición, mientras que otra tercera parte ve de forma optimista el cumplimiento de los acuerdos de paz. La tercera parte restante se divide entre los que piensan que es 
igual y los que no saben. Ciertamente, la población aparece dividida en partes proporcionales, pero el simple hecho de que el optimismo no prive en la mayoría cuestiona la marcha del proceso. El pesimismo de la tercera parte de la población parece indicar que para los salvadoreños, el cese de la guerra ya no es suficiente. Su insatisfacción está relacionada con las expectativas creadas por los acuerdos de paz, las cuales van desde el mejoramiento de las condiciones de vida de cada uno hasta el desarrollo social y político del país. Asi, pues, para muchos salvadoreños, los acuerdos no sólo han fallado al no dar paso a un nuevo país, sino que también han fracasado al no generar condiciones para progresar individualmente y para resolver los problemas principales de El Salvador (ECA, 1995, 555-556, pp. 63-64). En casos extremos, esta insatisfacción ha desembocado en disturbios callejeros violentos.

Indudablemente, es importante que los dirigentes de la ex guerrilla puedan participar plenamente en las discusiones de la asamblea legislativa o que como partido político gocen de libertad y que haya espacios para que las fuerzas sociales se expresen, pero esto no es suficiente. Ninguno de estos hechos pone en peligro la estructura tradicional del poder ni la forma de ejercerlo. Por eso mismo no está claro todavía hacia qué tipo de sociedad transita El Salvador, si a una democrática o a una autoritaria - con fachada democrática.

La democracia es incompatible con la elevada y acelerada concentración del capital existente. Para mantener esta dinámica es necesario ejercer el poder de manera autoritaria, puesto que de otro modo sería muy difícil controlar el malestar y la protesta popular. A más concentración de la riqueza, menos democracia y más autoritarismo. Al negociar los acuerdos de paz no se discutió un modelo económico orientado a erradicar las causas estructurales de la guerra y, en este sentido, a garantizar el ejercicio de la democracia. La discusión fue pospuesta para cuando se abrieran los espacios sociales en el país. Los artífices de los acuerdos consideraron que dicha discusión no les competía y por eso se limitaron a garantizar la apertura del espacio social para el debate público. Ahora, en teoría, la sociedad tendría a su disposición ese espacio para llevar a cabo la discusión pendiente sobre el ordenamiento social y económico.

En esta discusión, la Iglesia tiene una palabra importante que decir desde la desconfianza que el evangelio muestra hacia la riqueza y desde la condena que Juan Pablo II hace de las idolatrías del dinero, la ideología, la clase y la tecnología (Sollicitudo rei socialis, $\left.N^{o} 37\right)$ y más concretamente aún de la 'idolatría del mercado', que ignora la existencia de bienes que, por su naturaleza, no son ni pueden ser simples 
mercancias" (Centensimus annus, $N^{\circ} 40$ ). El Papa advierte severamente sobre "el afán de ganancia exclusiva" y "la sed de poder, con el propósito de imponer la propia voluntad" tan característicos del capitalismo y, para que no quede ninguna duda, añade que el capitalismo es inaceptable cuando pretende comprarlo todo "a cualquier precio" (Sollicitudo rei socialis, $\left.N^{\circ} 37\right)$.

Naciones Unidas ha cerrado su misión en El Salvador sin dejar consolidadas las instituciones que deberán asumir la responsabilidad para dar continuidad al proceso de transición, en concreto, la Policía Nacional Civil, la Procuraduría para la Defensa de los Derechos Humanos y el Organo Judicial (ver en esta edición el informe del Secretario General de Naciones Unidas al Consejo de Seguridad en "Documento especial"). Estas instituciones son claves para garantizar y defender los derechos humanos, para administrar justicia y para conducir la transición hacia la democracia. En todo ello, la Iglesia también tiene mucho que decir y exigir.

Durante su permanencia en el país, ONUSAL se ganó la credibilidad de la población y de las organizaciones populares, las cuales acudieron a ella buscando protección, amparo y ayuda en un sinnúmero de problemas, muchos de ellos incluso ajenos al mandato de la misión. En las huelgas, las tomas de edificios públicos y las protestas callejeras, la misión desempeñó un papel de primera importancia al contener la agresividad de las partes enfrentadas, al poner racionalidad en las demandas y en las respuestas, al agilizar los trámites y eliminar los obstáculos para restablecer la tranquilidad. En teoría, a las tres instituciones mencionadas arriba correspondería asumir estas responsabilidades tan delicadas, pero dada su inexperiencia, su falta de recursos y las maniobras para tergiversar su mandato -en especial el de la Policía Nacional Civil-, ¿quién asumirá la defensa de los derechos de la población? ¿Quién escuchará sus reclamos y quién les dará voz?

En el pasado reciente, a medida que el Estado se fue descomponiendo, víctima de un poder paralelo mucho más fuerte que lo convirtió en una mera fachada - tal como lo señala el informe de la Comisión de la verdad-, hasta el extremo de anular sus funciones institucionales, el arzobispado y el arzobispo de San Salvador asumieron la defensa de las víctimas y de sus derechos. Indudablemente, la institucionalidad del Estado salvadoreño se ha ido reconstituyendo a partir de la firma de los

Este elevado nivel de credibilidad es motivo de sano orgullo para la Iglesia, pero también implica una responsabilidad enorme para quienes están al frente de ella... 
acuerdos de paz, pero sus prácticas todavía no se ajustan a las leyes de la república, tal como se puede constatar cotidianamente en sus tres órganos. Nadie puede asegurar tampoco que si aumenta la conflictividad social a causa de las injustas políticas económicas del gobierno, los espacios abiertos no comiencen a cerrarse nuevamente. Las amenazas de los escuadrones de la muerte contra los delincuentes y jueces constituyen un presagio ominoso.

La Iglesia católica, y más concretamente la arquidiócesis, es una de las instituciones salvadoreñas que goza de más prestigio y credibilidad entre la población por su largo y probado compromiso con los pobres, las víctimas, la verdad y la justicia. Nadie debiera extrañarse, entonces, que si las instituciones estatales cierran sus puertas a las víctimas y a los pobres, al igual que en el pasado, éstas y éstos se vuelvan hacia el arzobispo y la arquidiócesis de San Salvador en busca de apoyo, de consuelo y de protección. Las instancias arquidiocesanas deben estar preparadas para asumir este reto, respondiendo, tal como lo hizo Jesús en su tiempo, eligiendo al hombre en lugar del sábado.

La Iglesia católica no puede desconocer que para la opinión pública salvadoreña es la institución que goza de más credibilidad. Entre los que le atribuyen mucha y algo de credibilidad se llega al 62.5 por ciento, muy lejos de las otras instituciones (ECA, 1995, 555-556, p. 68). Esto es sumamente importante para el futuro del pais, porque las instancias con mayor responsabilidad sobre la dirección del proceso de transición son, precisamente, las más cuestionadas en su credibilidad. Aparentemente, sólo las instituciones creadas a raiz de los acuerdos de paz mantienen cierto nivel de credibilidad en la población, aunque todavía no suscitan toda la confianza necesaria. Este elevado nivel de credibilidad es motivo de sano orgullo para la Iglesia, pero también implica una respon-

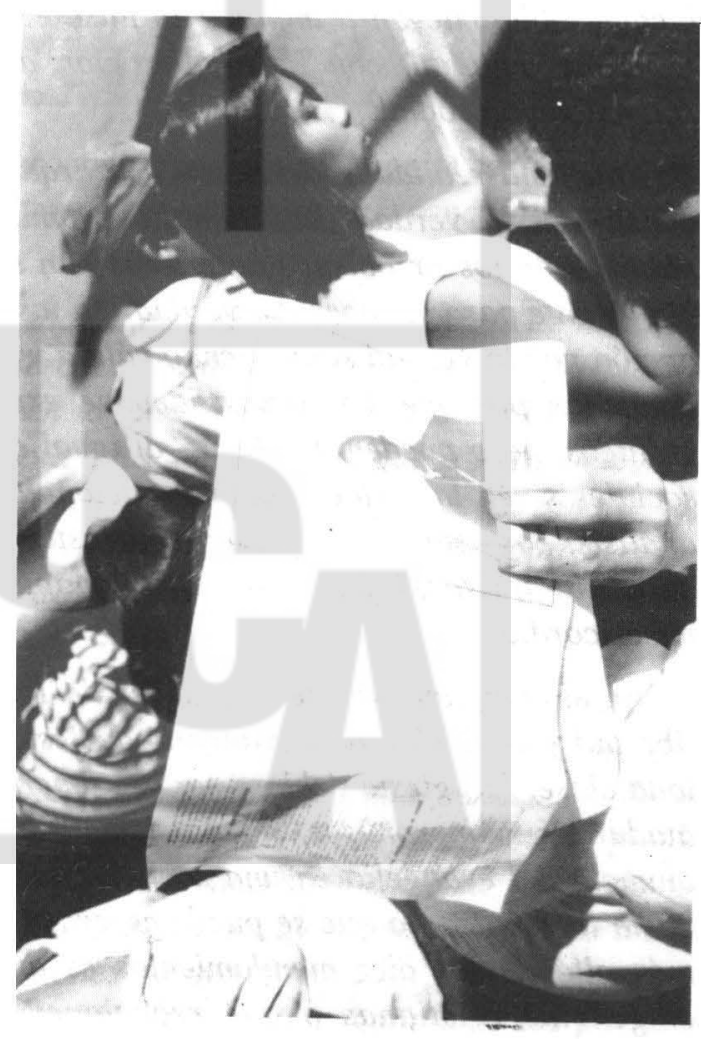


sabilidad enorme para quienes están al frente de ella, puesto que para la mayoría de la nación ella es signo de esperanza, de verdad y de justicia.

El tercer reto es mantener la opción por la verdad ante la corrupción, la mentira y el encubrimiento. Aunque en el país se han abierto espacios para la participación política y social, es claro que la mentira oficial sigue siendo una realidad constante para encubrir la corrupción, la injusticia e incluso el crimen. La mentira es tan corriente, la corrupción tan rampante y el encubrimiento institucional tan escandaloso que la Iglesia no puede dejar de optar por la verdad sin el riesgo de traicionar los principios evangélicos y perder credibilidad ante la nación. Más aún, los dos retos anteriores incluyen la opción por la verdad. No olvidemos que la verdad siempre está mucho más a favor de los pobres y las víctimas que del lado de sus opresores y verdugos. Con frecuencia, la verdad es lo único que las víctimas y los pobres tienen a su favor.

Se falsean las estadísticas oficiales que miden el crecimiento económico y sus beneficios, y se miente sobre la realidad de la transición política y sobre las acusaciones que se hacen contra los funcionarios públicos. Razones diversas que van desde presentar una imagen positiva del país para conseguir la aprobación internacional y atraer la inversión extranjera hasta los intereses políticos partidarios inconfesables, llevan a imponer lo falso como verdadero, la apariencia sobre la realidad, con la colaboración activa de algunos medios de comunicación social.

Ante esta realidad, la Iglesia y la arquidiócesis no pueden dejar de insistir en la verdad. Las homilías dominicales y las intervenciones públicas de los arzobispos anteriores han sido el referente eclesial más importante para conocer esa verdad. En las circunstancias actuales, esta opción por la verdad sigue siendo válida y necesaria. Claro, los obispos no tienen por qué ser necesariamente expertos en análisis sociales y políticos, pero pueden y deben -al igual que el Papa en las encíclicas sociales y en las relaciones internacionales-apoyarse en los mejores análisis, los cuales deben ser contrastados con la visión que da la cercanía pastoral a las mayorías populares y el principio de la misericordia.

En el cumplimiento de este deber, la lglesia debe ser un ejemplo de libertad y de fidelidad al evangelio de Jesucristo frente a los poderes de toda clase. La Iglesia debiera ser la primera en liberarse de todo tipo de ataduras y compromisos, siendo siempre fiel a la verdad. Más aún, del anuncio del evangelio en una sociedad tan poco fraternal y tan injusta como la nuestra, lo que se puede esperar de los ricos que no quieran ir más allá de los diez mandamientos es que se retiren tristes ante las exigencias cristianas o que reaccionen intentando desprestigiar a 
quienes anuncian

ese evangelio.

El cuarto desafío es trabajar por la reconciliación verdadera del país. Ciertamente, es un logro importante de los acuerdos de paz que los enemigos de antano, aparentemente irreconciliables, ahora aparezcan juntos en público y puedan discutir en la asamblea legislativa o en otros foros los problemas nacionales. Sin embargo, éste es sólo un primer nivel de reconciliación. Más aún, es un nivel insuficiente de cara a lo

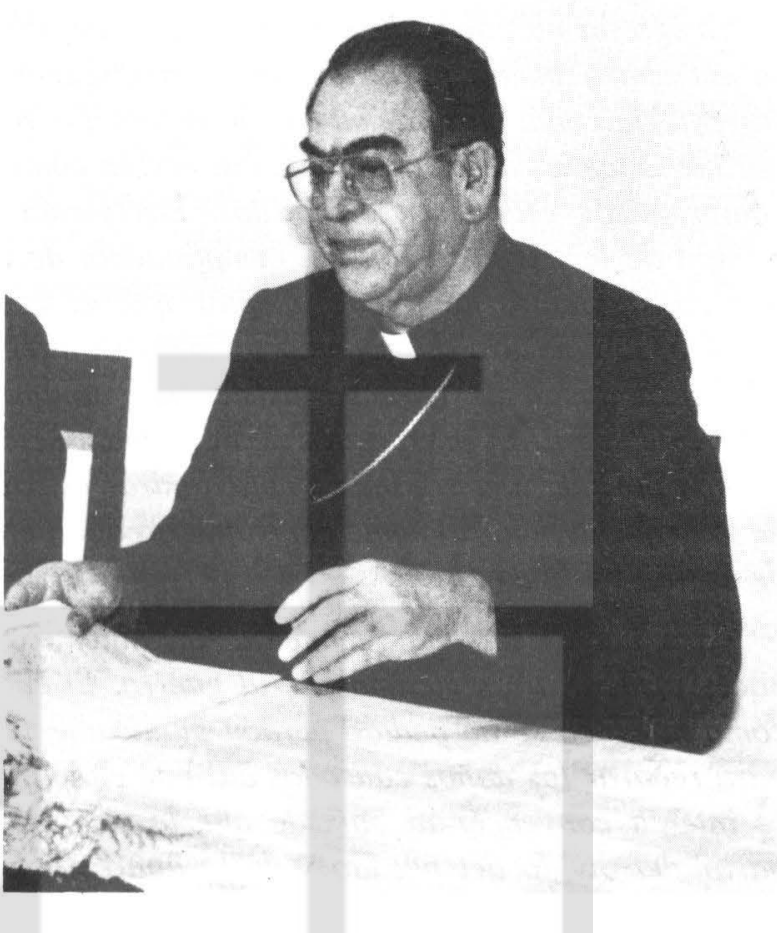
que debiera ser la auténtica reconciliación del país. En este sentido, es falso afirmar, fundamentado en este primer paso, que la reconciliación es una realidad en El Salvador.

La reconciliación está apenas empezada porque decenas de miles de ex combatientes de ambos ejércitos todavía no han sido incorporadas a la vida civil. Su reinserción en la vida social y familiar está pendiente, en parte, porque, por su propia naturaleza, este proceso toma tiempo $y$, en parte, por las implicaciones personales, económicas, sociales y psicológicas que intervienen. El retraso inexcusable en adoptar algunas medidas gubernamentales destinadas a acelerar este proceso de reinserción lo han hecho todavía más difícil de lo que ya es.

Al no haberse producido un triunfo militar y al no haber obtenido de las negociaciones beneficios inmediatos tangibles, algunas de las expectativas de los ex combatientes quedaron insatisfechas. Ni de la guerra ni de la negociación obtuvieron aquello que esperaban y por lo cual se enrolaron en ambos ejércitos. Aparentemente, su sacrificio ha sido en vano, pues al final se encuentran en la misma pobreza de antes. De esta manera, sus aspiraciones se ven frustradas y sobrevienen el desencanto y la desilusión ante la vida y el desengaño ante los partidos 
políticos y las instituciones estatales. La sensación de haber sido engañados es abrumadora. La pregunta desesperada que muchos se hacen es si valió la pena tanto sacrificio para tan poca cosa.

La Iglesia no puede desentenderse de esta dificil situación en la que se encuentra buena parte de los ex combatientes, sino que tiene que enfrentarla como parte de su misión reconciliadora. La tarea no es fácil porque todos los datos apuntan en dirección contraria, como si todos los compromisos estuviesen cumplidos. La Iglesia no puede caer en la trampa de la trivialización del cumplimiento de los acuerdos de paz y, por consiguiente, no puede aceptar que el cese del enfrentamiento armado, la apertura del espacio social para integrar a la ex guerrilla y la escasa ayuda de carácter asistencial, aunque indispensables, sean suficientes desde la perspectiva de la reconciliación. Aceptar esto es una trampa porque, una vez más, implica mirar el país desde la perspectiva de la pequeña minoría como contrapuesta a la perspectiva de la mayoría de los hijos e hijas de Dios.

Para hablar de una reconciliación auténtica, además, habría que hacer justicia a las víctimas de la guerra, lo cual no se ha hecho, así como tampoco se ha pedido perdón públicamente ni se han dado pasos para reparar los daños causados durante el conflicto armado. Más bien se intenta convencer al país de que la reconciliación es un hecho a partir del olvido del pasado y de la aparición pública de las cúpulas políticas. La campaña lanzada por algunos medios de comunicación social en contra de Mons. Romero, de Mons. Rivera y de la Compañía de Jesús a raíz del nombramiento del nuevo arzobispo muestra el odio que anida en el corazón de algunos sectores sociales, producto de su temor a perder sus privilegios y de la persistencia de actitudes crueles e injustas, impenitentes e irrendentas. Al igual que en el pasado, la campaña se caracteriza por la irracionalidad, la tergiversación y la ignorancia malévola. Paradójicamente, con alguna reconocida excepción, esto sectores se han olvidado del daño que la guerrilla pudo haberles causado durante el conflicto, pero no han perdonado aún la opción de los dos arzobispos anteriores y de los jesuitas por las mayorías empobrecidas víctimas de la violencia.

Este odio desenfrenado y la intolerancia que muestra son prueba que en El Salvador todavía no ha habido una reconciliación verdadera, pues persiste el conflicto fundamental, la injusticia. La clase dominante ha olvidado "generosamente" el pasado de la ex guerrilla tal vez porque la percibe cada vez menos comprometida con la causa y los intereses populares o porque ya no la considera una amenaza real. En cambio, a los dos últimos arzobispos y a los jesuitas no les perdona su fidelidad a la opción por los pobres. Pensaban ingenuamente que esa opción 
obedecía a su identificación con el marxismo y, en consecuencia, creyeron que una vez que los socialismos históricos se habian derrumbado, dicha opción también desaparecería.

Juan Pablo II afirma exactamente lo contrario en la Centesimus annus ( $\left.N^{\circ} 35\right)$, donde considera inaceptable "que la derrota del socialismo deje al capitalismo como único modelo de organización económica". Ya Pablo VI, citando a Pío XI, advirtió que el "liberalismo sin freno" conducía al "imperialismo "internacional del dinero"" (Populorum progressio, $\left.N^{\circ} 26\right)$. "Por desgracia", explica Pablo VI en la encíclica citada, "ha sido construido un sistema que considera el lucro como motor esencial del progreso económico; la concurrencia, como ley suprema de la economía; la propiedad privada de los medios de producción, como un derecho absoluto, sin límites ni obligaciones" (ib.). Así, pues, según esta doctrina de los papas, los injustamente denigrados por ser teólogos de la liberación están más próximos al magisterio pontificio que sus detractores.

Ciertamente, ha habido acercamientos importantes entre los antiguos enemigos, pero los ricos y poderosos todavía no se han acercado a las mayorías pobres para dar comienzo a la reconciliación verdadera. Al contrario, los ricos tienden a ser cada vez más ricos y excluyentes, mientras los pobres tienen que aguardar lo que les sobre a los primeros. La parábola del rico Epulón, quien vivía en la opulencia y banqueteaba todos los días, y Lázaro, quien a su puerta esperaba lo que sobrase, recoge con fidelidad inigualable la situación actual de El Salvador y de Centroamérica. De hecho, el mayor obstáculo del gobiemo para cumplir con los compromisos adquiridos en los acuerdos de paz orientados a beneficiar a los ex combatientes y para poder lanzar un auténtico programa de inversión social es la falta de recursos económicos. Y no es que El Salvador no disponga de ellos, sino que están concentrados en muy pocas manos.

Todavía estamos lejos de que los militares salvadoreños, siguiendo el ejemplo de sus colegas argentinos, por lo menos reconozcan que cometieron errores y acciones horrendas y que prometan públicamente que nunca, bajo ninguna circunstancia, volverán a permitir violar el derecho. En este contexto de la reconciliación, la Iglesia está obligada a llamar continuamente a los militares a la conversión. Estamos más lejos aún de que los ricos se conviertan y opten por renunciar voluntariamente a algunas de sus riquezas y a algunos de sus lujos para poder aliviar al menos los efectos devastadores de la pobreza de sus compatriotas. La Iglesia debiera asumir con decisión este desafio de la reconciliación nacional, señalando los obstáculos que la impiden e insistiendo en su necesidad. No se debe relegar al olvido que los obispos de la arquidiócesis hicieron un esfuerzo gigantesco para encontrar una 
salida negociada a la guerra, y en buena medida, su fin se debió a ellos y a los innumerables mártires. Trabajar por la reconciliación verdadera es dar continuidad a esa obra de la paz.

Mucho queda por hacer en este campo de la reconciliación, que comprende varios niveles y complejidades. La tolerancia y la apertura actuales son sólo un primer paso. Y un primer paso débil porque se ve constantamente amenazado por la violencia y el autoritarismo. La nación tiene que reconciliarse consigo misma y con su pasado, lo cual implica establecer y reconocer la verdad sobre lo que sucedió realmente. El intento por olvidar, legitimado por la amnistía, es insuficiente porque sanciona una gran injusticia y porque mientras el pasado no sea enfrentado, sus fantasmas seguirán acechando el presente y el futuro. El Salvador todavía no ha sacado en limpio las lecciones de su pasado reciente y se niega a aprender de ellas.

Es necesario iniciar un proceso de perdón real, cuyo punto de partida sea el reconocimiento de los errores, la muestra de un arrepentimiento sincero y la promesa de no volver a cometerlos. Los obispos argentinos, aunque tarde, están invitando a todos los implicados en la guerra sucia a hacer un examen de conciencia riguroso y a pedir perdón públicamente. Asimismo, es indispensable concientizar a la población sobre el final del enfrentamiento militar para despolarizar y desideologizar, abriendo espacios para el diálogo y la tolerancia. El resentimiento y la venganza pueden estar detrás de algunos de los asesinatos que se están dando en las pequeñas comunidades, donde todos se conocen. Finalmente y como requisito previo para reconstruir el país sobre unas bases más sólidas a las existentes antes del conflicto, hay que crear conciencia de que los problemas nacionales y su solución deben ser discutidos amplia y abiertamente.

El quinto desafío de la Iglesia consiste en profundizar la evangelización. Este desafío no está desligado de los anteriores ni es menos importante. Aparentemente, la evangelización constituiría la actividad eclesial por antonomasia. De tal manera que la Iglesia debiera dedicarse exclusivamente a predicar el evangelio y a administrar sacramentos, desentendiéndose de la realidad en la cual se encuentra inserta. Pero la evangelización no puede desentenderse de esa realidad, porque tiene que encarnarse en ella para transformarla. Nada de esa realidad es extraño a la evangelización, declara Pablo VI en la Evangelii Nuntiandi ( $N^{o} 30$ ) y Juan Pablo II, en la Sollicitudo rei

\section{La Iglesia debiera ser la primera en liberarse de todo tipo de ataduras y compromisos, siendo siempre fiel a la verdad.}


socialis, recalca que la preocupación por lo social "forma parte de la misión evangelizadora de la Iglesia" ( $\left.N^{\circ} 41\right)$ y tiene "el valor de un instrumento de evangelización" (Centesimus annus, $N^{\circ} 54$ ).

Por lo tanto, evangelizar hoy en El Salvador no puede hacerse al margen de los grandes problemas nacionales, sino desde ellos. En Santo Domingo, el episcopado latinoamericano recordó que la evangelización es "respuesta a los problemas que presenta la realidad de un continente en el cual se da un divorcio entre fe y vida hasta producir clamorosas situaciones de injusticia, desigualdad social y violencia" ( $\left.N^{\circ} 24\right)$. Para salvar, la palabra tiene que hacerse historia, liberando de las opresiones y violencias concretas. Por lo tanto, el episcopado latinoamericano considera como un "deber y derecho estar presente en este campo de la realidad porque el cristianismo debe evangelizar la totalidad de la existencia humana, incluida la dimensión política" (Puebla, $N^{\circ} 515$ ).

Si la Iglesia asume los desafios anteriores, es decir, si se compromete con las mayorías empobrecidas y violentadas, si se pronuncia contra el autoritarismo y en favor de la democracia como una forma de ejercer el poder más apegada al derecho de las naciones, si opta por la verdad en contra de la mentira, si promueve la reconciliación contra el olvido interesado y la acumulación injusta de riqueza y poder, entonces, evangelizará toda la rea. lidad salvadoreña y el país entero. Estos desafíos le brindan una oportunidad única para anunciar continuamente la buena noticia de Jesús ahi donde predominan las malas realidades y para luchar por quitar el pecado de este mundo social.

La preocupación por la conversión personal de todos los salvadoreños no debe convertirse en un obstáculo para desentenderse de estos compromisos evangelizadores de alcance nacional porque, tal como señala la Sollicitudo rei socialis, las acciones personales se traducen

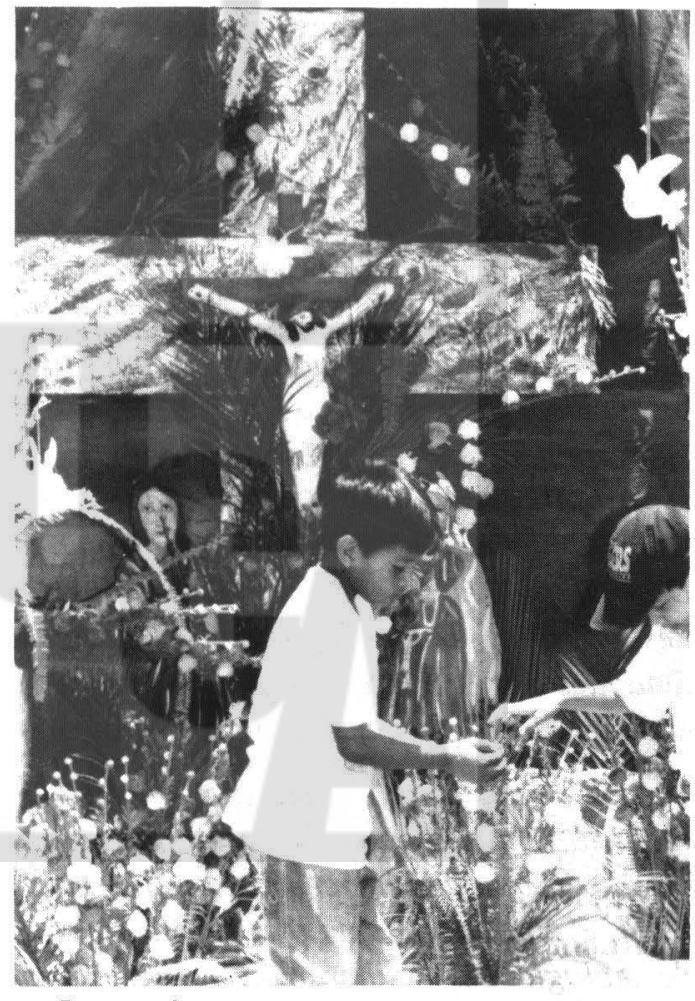


en estructuras de pecado que se consolidan y se vuelven ocasión para cometer otros pecados al condicionar la conducta de las personas ( $N^{\circ}$ 36). Por consiguiente, si se quiere erradicar el pecado de la sociedad es indispensable atender a su doble dimensión personal y social. La presencia activa de la lglesia en medio de los problemas nacionales moverá a muchos a la conversión personal y a otros les recordará constantemente la necesidad que tienen de convertirse.

Asimismo, las conversiones personales servirán como aliciente para trabajar por una sociedad más justa, fraternal y solidaria, y una sociedad en vias de liberarse de la injusticia y del pecado facilitará la vida cristiana de todos. "La Iglesia", escribe Paulo VI en la Evangelii Nuntiandi, "tiene el deber de anunciar la liberación de millones de seres humanos, entre los cuales hay hijos suyos; el deber de ayudar a que nazca esta liberación, de dar testimonio de la misma, de hacer que sea total" ( $\left.N^{\circ} 30\right)$. Por eso, la evangelización exige la unificación del servicio de la fe y la promoción de la justicia. La justicia es esencial a la fe y a la Iglesia, y es exigida por la realidad salvadoreña actual. En esta exigencia se encuentran en juego la credibilidad de la Iglesia y, desde una perspectiva humana, su futuro. Si la Iglesia evangeliza desde la fe y la justicia tendrá credibilidad; en cambio, si abandona esta doble exigencia, perderá credibilidad y eficacia en un país como El Salvador, donde predomina la injusticia.

Si la Iglesia asume todos estos desafíos se le podría presentar otro más: la persecución. La arquidiócesis tiene una larga experiencia en esto. El ministerio profético de sus obispos, sacerdotes, religiosas $e$ innumerables agentes de pastoral le trajo la persecución y el martirio. La infame campaña que denigra a Mons. Romero, a Mons. Rivera y a la Compañia de Jesús manifiesta la añoranza por los tiempos de las "dos esferas", cuando el Estado y la Iglesia se habian repartido las competencias y las respectivas jurisdicciones. Según esta tesis, al primero le correspondería lo temporal y político, mientras que a la segunda, lo espiritual y religioso. Asi definidas, ninguna de estas dos esferas o ámbitos debía interferir en la otra. Como el origen y el fin de ambas era Dios mismo, él se encargaría de que el curso de las dos llegara a su destino final. De esta manera, la Iglesia podía desarrollar sus actividades libre de interferencias estatales, pero también dejaba al Estado el campo libre para que actuara según sus conveniencias e intereses.

Las plumas que exigen una lglesia ajena a la realidad son las que rechazan la teología de la liberación en nombre de una supuesta ortodoxia que desconocen clara e interesadamente. En la instrucción de 1984, el Vaticano llama efectivamente la atención sobre "ciertas formas de teología de la liberación" porque recurren de "modo insuficiente- 


\section{Evangelizar hoy en El Salvador no puede hacerse al margen de los grandes problemas nacionales, sino desde ellos.}

mente crítico, a conceptos tomados de diversas corrientes del pensamiento marxista" (Instrucción sobre algunos aspectos de la teología de la liberación, "Introducción", 1984). Por consiguiente, el Vaticano llama la atención sobre "ciertas formas" y no sobre toda la teología de la liberación como suelen afirmar con ligereza sus detractores salvadoreños.

Más aún, el documento agrega inmediatamente después que esta llamada de atención "de ninguna manera podrá servir de pretexto para quienes se atrincheran en una actitud de neutralidad y de indiferencia ante los trágicos y urgentes problemas de la miseria humana" (ib.). "Más que nunca", continúa el texto, "la Iglesia se propone condenar los abusos, las injusticias y los ataques a la libertad... y luchar... por la defensa y promoción de los derechos del hombre, especialmente en la persona de los pobres" (ib.). Dos años más tarde, el Vaticano, al volver sobre el tema, reafirmó que "la Iglesia no duda en denunciar las condiciones de vida que atentan a la dignidad y a la libertad del hombre" (Instrucción sobre libertad cristiana y liberación, 1986). Asimismo, se desconoce que Juan Pablo II declaró en Brasil que la teología de la liberación es necesaria, útil y oportuna para la Iglesia universal.

En realidad, a quienes orquestan la campaña contra la teología de la liberación no les interesan las implicaciones teológicas de la liberación, sino rechazar como legítimo y cristiano que los pobres luchen por ella, en lugar de esperar a que ésta les venga dada como resultado de la suma de las conversiones individuales de los poderosos. Trabajar por "todo aquello que los condena a quedar al margen de la vida: hambres, enfermedades crónicas, analfabetismo, depauperación, injusticia en las relaciones internacionales y especialmente en los intercambios comerciales" (Evangelii Nuntiandi, $N^{0} 30$ ) sería una interferencia política inaceptable para los poderosos. Pero se olvidan que es igualmente político desentenderse de todos esos males. La diferencia, muy importante por cierto, está en la opción que hace la Iglesia.

La teología de la liberación irrita a la clase dominante y a sus ideólogos porque les recuerda constantemente que el plan de Dios comprende compartir los recursos de la creación, convivir como hermanos y hermanas para poder llamar a Dios Padre con verdad y hacer de la solidaridad fraternal el fundamento de las relaciones personales, familiares, nacionales e internacionales. Este plan se opone frontalmente 
a la dinámica de acumulación capitalista que más bien promueve el egoísmo, la competencia y el derroche. El humanismo cristiano y la deshumanización capitalista son evidentemente incompatibles. Se equivocan quienes piensan que el derrumbamiento de los socialismos históricos implica automáticamente la consagración del capitalismo y su idolo el mercado (Centesimus annus, $N^{\circ} 35$ ).

Los detractores de la teología de la liberación y presuntos defensores de la ortodoxia de la Iglesia han comprendido bien la paradoja y a eso se debe que reaccionen tan visceralmente. La campaña actual contra dicha teología es similar a las del pasado que desembocaron en expulsiones, capturas, torturas, desapariciones forzadas y asesinatos. El odio a la justicia es el que ha producido tantos mártires, hombres y mujeres generosos quienes, movidos por su fe, se entregaron sin reservas a trabajar por los demás, por la justicia, por la verdad y por la paz. La Iglesia salvadoreña no debe tener miedo a la persecución ni al martirio, sino a no ser fiel al evangelio por pactar con los poderes de este mundo. La gloria de esta Iglesia son sus mártires. Por eso los recuerda con cariño, conmemora su martirio con dolor y alegría pascual y ellos le inspiran esperanza para mantener su compromiso.

Los mártires impiden que la Iglesia caiga en la trivialización de la cultura neoliberal. Ellos son los grandes abogados de la verdad. Nos dicen que la verdad y el amor son posibles. En El Salvador, los mártires no han sido masoquistas, ni fanáticos religiosos. No se mostraron ansiosos por derramar sangre, ni la ajena ni la propia. Han sido cristianos de compasión y misericordia. El martirio ha sido expresión de su gran amor a quienes sufren pobreza, opresión, represión y muerte. Los mártires no dieron su vida por conseguir algo para ellos, sino para que las mayorías tuviesen vida.

La Iglesia, por su propia naturaleza, está obligada a generar esperanza. En la tradición martirial de la arquidiócesis hay una fuente inagotable de esperanza, puesto los principios evangélicos se historizan de manera privilegiada en los mártires. No hay que conformarse con lo que los políticos o la comunidad internacional estén dispuestos a conceder, sino que se debe trabajar por la utopía que se quiere conseguir. La utopía jamás será regalada, sino que hay que luchar por ella, arrebatándola. En eso consiste nuestra colaboración con el comienzo del cumplimiento de las promesas de Dios.

Indudablemente, para asumir todos estos desafios es necesario unir fuerzas. Aunque aparentemente no lo parezca, la Iglesia salvadoreña, y en particular la arquidiócesis de San Salvador, cuenta con innumerables recursos, instituciones y experiencia. En este sentido, no parte de cero. Lo que ahora hace falta es claridad en el diagnóstico de la realidad 
nacional, firmeza en el compromiso cristiano y generosidad en la entrega a la causa de la fe y la justicia. En la arquidiócesis de San Salvador peregrina una lglesia viva, evangelizadora, profética y martirial. Ha hecho presente al Dios de Jesús en las encrucijadas de la historia nacional y ha sabido llevar hasta ese Dios los clamores y las esperanzas del pueblo salvadoreño. Lo ha hecho con errores y fallos, pero también con una gran fe, con una esperanza puesta a prueba por la adversidad y con el compromiso del amor mayor.

Recordar esta verdad, valorarla, dar gracias por ella y ponerla a producir es muy importante en estos momentos de relevo en la arquidiócesis de San Salvador. Es importante también para hacer un alto y ser conscientes del camino recorrido y de los desafios planteados por la realidad actual de El Salvador. La Iglesia que peregrina en El Salvador no puede abandonar ahora al pueblo de Dios, no puede cejar en su empeño para iluminarlo y guiarlo hacia el reino del Padre, un reino de verdad, justicia y paz.

San Salvador, 12 de mayo de 1995. 